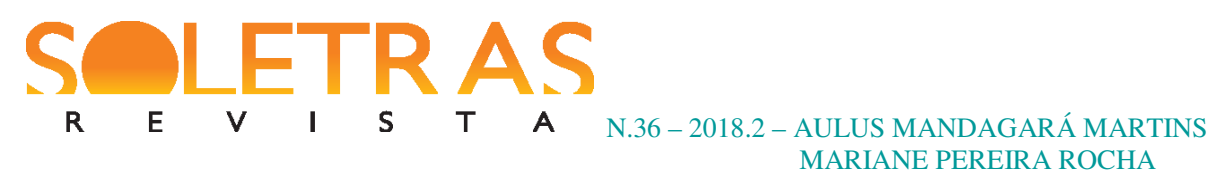

\title{
Museu de momentos: poesia, memória e fotografia em Ana Martins Marques
}

\author{
Aulus Mandagará Martins ${ }^{1}$ \\ Mariane Pereira Rocha ${ }^{2}$
}

\begin{abstract}
Resumo: Este ensaio propõe-se a analisar as relações entre poesia, memória e fotografia na obra poética de Ana Martins Marques, particularmente nos poemas "Museu" e "Aparador", de O livro das semelhanças (2015). Interessa-nos investigar de que modo a temática da memória se apresenta na poesia de Marques, sobretudo no que diz respeito à fotografia enquanto dispositivo de armazenamento do passado. Para tanto, as reflexões de Agamben $(2007 ; 2009)$ sobre a museificação do mundo e a fotografia servem como suporte teórico desta reflexão. Verificamos, através deste estudo, que a fotografia, nos poemas de Ana Marques, não apenas procura captar ou registrar os fatos significativos de uma existência, mas, sobretudo, aquilo que é banal, insignificante e, até mesmo, o não fotografado. Assim, a poeta propõe um museu de ninharias, de instantes banais, subvertendo o sentido comum atribuído à prática dos museus como locais de armazenamento de objetos e obras representativas da história e dos movimentos culturais ou artísticos.
\end{abstract}

Palavras-chave: Poesia brasileira contemporânea. Fotografia. Memória. Ana Martins Marques.

\section{Introdução}

Se, conforme afirma Giorgio Agamben (2009), o contemporâneo parece ser aquele que somente por um desencontro ou um desajuste compreende o seu tempo, vemos em $O$ livro das semelhanças (2015) de Ana Martins Marques a tentativa de discutir a contemporaneidade a partir de uma perspectiva mais voltada para os eventos menores da existência, as coisas insignificantes do cotidiano. Nesse sentido, sua poesia não enfatiza tanto a necessidade do rememorar ou preservar a memória daquilo que não pode ou deve ser esquecido, mas, justamente, reflete sobre a dispersão do vivido, sobre, por assim dizer, a necessidade do esquecimento.

Essa postura da poeta pode ser contrastada com importantes reflexões oriundas do campo da historiografia, que procuram destacar a relevância da rememoração. É o caso, por

\footnotetext{
${ }^{1}$ Doutorado em Letras pela Universidade Federal do Rio Grande do Sul (UFRGS). É professor associado do Centro de Letras e Comunicação da Universidade Federal de Pelotas (UFPel), exercendo atividades de docência em graduação e pós-graduação. É professor-orientador do Programa de Pós-Graduação em Letras (Área de Literatura Comparada). É coordenador do Programa de Pós-Graduação em Letras da Universidade Federal de Pelotas (UFPel), Pelotas, RS, Brasil. E-mail: aulus.mm@gmail.com.

${ }^{2}$ Mestranda em Literatura Comparada pela Universidade Federal de Pelotas (UFPel), Pelotas, RS, Brasil. Email: marianep.rocha@gmail.com.
} 


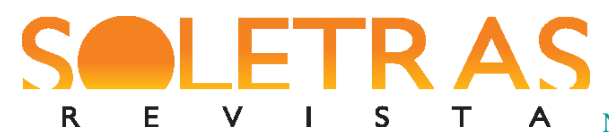

$\begin{array}{lllllllll}\mathbf{R} & \mathbf{E} & \mathbf{V} & \mathbf{I} & \mathbf{S} & \mathbf{T} & \mathbf{A} & \mathrm{N} .36-2018.2 \text {-AULUS MANDAGARÁ MARTINS }\end{array}$

MARIANE PEREIRA ROCHA

exemplo, de Dominick La Capra (2009), cujo pensamento destaca o papel social da memória em não deixar cair no esquecimento eventos que, se não fossem constantemente relembrados, correriam o risco de repetir-se, como o Holocausto.

Assim, interessa-nos, nos limites deste ensaio, discorrer sobre essa articulação da memória e do esquecimento, sobretudo quanto ao uso que a poeta faz da fotografia como um dispositivo que, ao mesmo tempo em que possibilita capturar e registrar a memória, evidencia suas falhas e limitações.

\section{Ecos de um cotidiano: museu de momentos}

Sem a pretensão de identificar movimentos ou tendências, a obra de Ana Marques vincula-se àquele traço da poesia moderna que extrai da experiência cotidiana os elementos de sua poética. Em seu ensaio sobre a obra de Charles Baudelaire, Walter Benjamin (2015) identifica em As flores do mal a transformação pela qual a poesia passou em virtude da alteração na vida contemporânea. Um poema que ilustra a modernidade do poeta francês é "O albatroz" (BAUDELAIRE, 1985, p. 111), em que o grande pássaro dos mares, impossibilitado de voar, sofre, por parte dos marinheiros, toda sorte de humilhação no convés do navio. Assim, tomando o albatroz como uma alegoria do poeta moderno, este, caindo das alturas, encontra agora um lugar junto às massas, como consequência da perda do prestígio que outrora tinha. A modernidade se apresenta, dessa forma, como a situação em que poesia e poeta integram-se ao ritmo da vida contemporânea, em que o poeta não é mais um sujeito eleito pelas musas, mas o homem mundano, que se encontra no mesmo patamar de toda a gente comum, e cuja poesia deve alimentar-se justamente dessa experiência da vida comum das ruas.

Ana Martins Marques dialoga com essa tradição de uma poética das miudezas e singularidades do cotidiano. Vale lembrar que, nesse contexto, conforme Beatriz Resende (2007), uma das marcas de nossa contemporaneidade é a presentificação, a urgência de expressar o aqui e o agora. No entanto, essa presentificação não rasura, pelo menos na obra de Marques, o tempo vivido e o aqui e o agora interpelam a experiência de outros tempos e lugares. Em "Museu", fica evidente o elogio que a poeta faz a tudo que nos é próximo, conhecido e banal: 


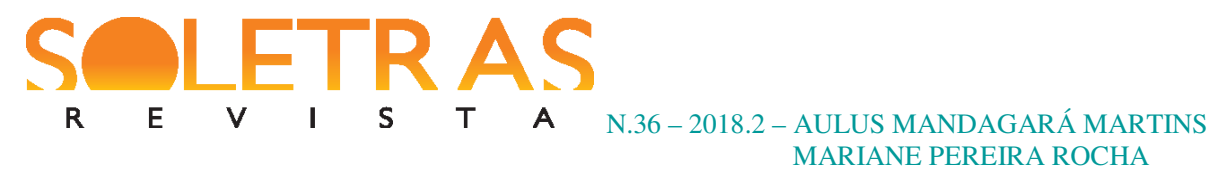

Se houvesse

um museu

de momentos

um inventário

de instantes

um monumento

para eventos

que nunca aconteceram

se houvesse

um arquivo

de agoras

um catálogo

de acasos

que guardasse por exemplo

o dia em que te vi atravessar a rua

com teu vestido mais veloz

se houvesse

um acervo

de acidentes

um herbário

de esperas

um zoológico

de ferozes alegrias

se houvesse

um depósito

de detalhes

um álbum

de fotografias

nunca tiradas

(MARQUES, 2015, p. 87-8)

O título do poema, com o que se segue, provoca um estranhamento no leitor. Ainda carregamos em nosso imaginário a ideia de que os museus são lugares onde se armazenam as relíquias dos importantes acontecimentos do passado, todos aqueles objetos que ilustram ou registram algo de representativo, no campo da história, da ciência ou das artes. Ainda pensando nesse imaginário, é oportuno lembrar que "museu" é o templo das musas, repositório das oferendas às divindades do mundo clássico. Ana Marques propõe, contudo, a existência de um outro museu, que guardaria "momentos" e "instantes". Ela não especifica 


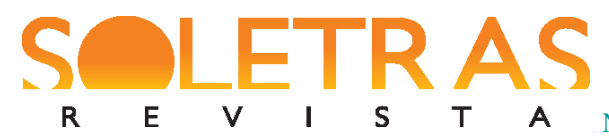

N.36 - 2018.2 - AULUS MANDAGARÁ MARTINS

MARIANE PEREIRA ROCHA

quais momentos ou instantes seriam esses, mas sugere-se, por contraste a esse imaginário, que seriam aqueles que normalmente não encontram lugar de destaque quando se registra o passado. Esse "inventário de instantes" daria conta dos acontecimentos mais banais, que passariam despercebidos para o historiador das "grandes histórias", quer dizer, tudo aquilo que, a princípio, fugiria ao interesse das musas, tudo aquilo cujo destino seria o esquecimento e a dispersão.

O museu que Ana Marques imagina desestabiliza, portanto, a concepção de museu como o templo dos grandes eventos e obras representativas do passado. Trata-se, agora, da possibilidade de reordenar e ressignificar eventos e objetos a partir de uma ótica particular, íntima e subjetiva, aquilo que é importante ou não para o sujeito, independentemente de merecer estar ou não em um museu, em virtude de sua relevância histórica, social ou artística. Entretanto, é importante observar que esse museu é uma potencialidade, um desejo que permanece no terreno da hipótese, certamente sem perspectiva de realização ("se houvesse"). O poema trabalha esse paradoxo de um museu que poderia existir e que, existindo, poderia constituir-se em um "monumento / para eventos / que nunca aconteceram". De qualquer forma, seja de acordo com a concepção clássica de templo das musas, seja na potencialidade aspirada pelo eu lírico, o museu sempre opera um deslocamento de um objeto, que é retirado de seu contexto, de seu uso corrente, e posto em um lugar que pertence à ordem do sagrado, nem tanto por ser uma oferenda às musas, mas sobretudo pelos novos significados que lhe são atribuídos a partir dessa posição privilegiada que é estar em um museu.

Agamben, no ensaio "Elogio da profanação", discute a função dos museus, ou mais precisamente, a "museificação do mundo", no sentido em que "Museu não designa um lugar, ou um espaço físico determinado, mas a dimensão separada para a qual se transfere o que há um tempo era percebido como verdadeiro e decisivo, e agora já não é” (AGAMBEN, 2007, p. 73). Em suma, conclui o filósofo italiano, "tudo hoje pode tornar-se Museu, na medida em que esse termo indica simplesmente a exposição de uma impossibilidade de usar, de habitar, de fazer experiência" (2007, p. 73). Assim, colocar um objeto em um museu significa retirá-lo do uso comum, afastá-lo do mundo, conferir-lhe destaque ou distinção justamente porque encontra-se afastado da vida cotidiana. Muito embora o museu proposto no poema de Ana Marques configure-se na coleção de objetos banais ou até mesmo inexistentes ("fotografias nunca tirada"), trata-se ainda de uma museificação, uma vez que, neste gesto de selecionar um objeto para o museu sempre está implicado um deslocamento, uma reordenação, cuja 


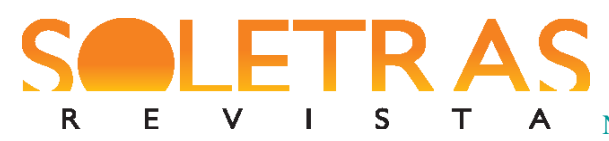

N.36 - 2018.2 - AULUS MANDAGARÁ MARTINS

MARIANE PEREIRA ROCHA

consequência é, em última análise, sua retirada do mundo cotidiano, tornando-o, pois, inacessível ao uso ordinário. Talvez por isso mesmo que o museu sonhado pela poeta deva permanecer como uma potencialidade, posto que não se deseja separar-se dos objetos, "momentos" e "instantes" selecionados.

Dessa maneira, entende-se o paradoxo que sustenta a ideia desse museu de "agoras" e “acasos". O desejo de museificar as coisas banais e pequenas do cotidiano diz respeito, de um lado, ao desejo, justamente, de conferir destaque a todas as coisas que, por pequenas e banais que sejam, poderiam cair no esquecimento. Por outro lado, se houvesse tal museu, a poeta perderia o vínculo com os objetos que pretende manter junto a si. Assim, o "vestido mais veloz", do qual se tem o registro fugaz na memória, se guardado em um museu, estaria a salvo da dispersão do esquecimento, mas, de igual forma, por estar em um museu, deixaria de pertencer a sua memória, tornando-se, pois, um objeto museificado, vale dizer, não mais acessível ao uso dessa memória particular.

\section{Fotografias nunca tiradas}

Ao lado do paradoxo desse museu que deveria existir para preservar os objetos, mas se existisse retiraria esses objetos do mundo do sujeito, o poema de Ana Marques trabalha ainda outra impossibilidade: o álbum de fotografias nunca tiradas. A referência ao álbum de fotografias nos remete ao dispositivo cultural cuja função é conservar as lembranças dos momentos especiais de uma pessoa ou família, festas de aniversários, casamentos, formaturas, viagens de férias. A princípio, como lembra Arlindo Machado (2015), não existe fotografia não tirada, uma vez que uma foto é o resultado de um processo mecânico, ótico, químico ou digital, que culmina na materialidade do registro do referente colocado diante da lente de uma máquina fotográfica. Essas fotografias não tiradas corresponderiam a momentos que não seriam importantes o suficiente para merecerem o registro fotográfico, aqueles fatos repetitivos do cotidiano desprovidos de um especial interesse. Da mesma forma que no paradoxo do museu das coisas insignificantes, em que a poeta reveste de relevância objetos banais, aqui temos um movimento semelhante, pois são justamente aqueles momentos que não foram fixados em uma fotografia que chamam sua atenção, que mereceriam destaque no museu sonhado. 


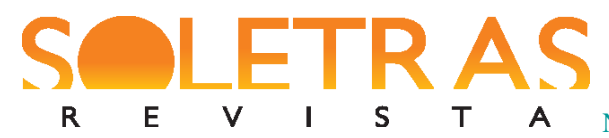

Em "Pequena história da fotografia", Walter Benjamin já assinalava o caráter errático da técnica fotográfica, ao propor a noção de inconsciente ótico. Em vez de mostrar a realidade tal qual ela é ou supostamente seria, o filósofo alemão observa que a fotografia impele o observador a uma

[...] necessidade irresistível de procurar nessa imagem a pequena centelha do acaso, do aqui e agora, com a qual a realidade chamuscou a imagem, de procurar o lugar imperceptível em que o futuro se aninha ainda hoje em minutos únicos, há muito extinto, e com tanta eloquência que podemos descobri-lo, olhando para trás (BENJAMIN, 1985, p. 94).

Nesse sentido, a fotografia, através de seus recursos técnicos específicos, proporciona ao observador uma determinada experiência, que é a de vislumbrar aquilo que se oculta na realidade e que somente se torna perceptível ao olhar pela imagem fotografia. A analogia entre a fotografia e a psicanálise aponta para a descontinuidade entre o conteúdo manifesto e o conteúdo latente que toda imagem comportaria. A fotografia revela (no sentido de descobrir algo oculto e também no sentido técnico da palavra, a ação de fixar a imagem, através de determinados agentes ou produtos químicos, no papel) a "pequena centelha do acaso", porque, ao operar um trabalho do inconsciente, permite o acesso a zonas obscuras que o olhar não consegue captar. Justamente por fixar e congelar um instante, a fotografia propicia a descoberta daqueles "momentos únicos" que fugiram à percepção do sujeito imerso no ritmo veloz da vida moderna. $\mathrm{O}$ inconsciente ótico revela, portanto, algum aspecto da realidade que, diante da fugacidade da vida, não pode ser plenamente apreendido. Graças, contudo, à descontinuidade do tempo, o passado que se torna presente na fotografia, criam-se as condições para que a atenção do olhar se concentre no detalhe antes desapercebido, mas agora revelado e dotado de nova e importante significação.

Em outro ensaio incluído em Profanações, “O Dia do Juízo”, Agamben reflete sobre a natureza da imagem fotográfica, identificando seus dois aspectos fundamentais: o gesto e a exigência. Por gesto, o filósofo italiano entende a capacidade que tem a fotografia de recolher os vestígios da vida que estão sempre ameaçados de se perderem. Assim, uma foto restaura e salva da dispersão aqueles gestos banais e insignificantes que, de toda maneira, "resumem em si o sentido de toda uma existência" (AGAMBEN, 2007, p. 28). Dito por outras palavras, o instante capturado pela imagem fotográfica remete a uma "infinita recapitulação de uma existência" (2007, p. 28). Outro aspecto ligado à fotografia é a exigência: "o sujeito 


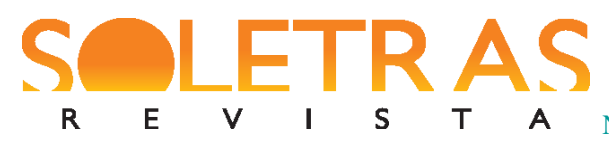

N.36 - 2018.2 - AULUS MANDAGARÁ MARTINS

MARIANE PEREIRA ROCHA

fotografado exige algo de nós” (2007, p. 29). Trata-se, pois, de uma espécie de resistência do objeto ou pessoa retratada que "exigem não serem esquecidos" (2007, p. 29). Há certamente uma reminiscência benjaminiana nesses conceitos de gesto e de exigência, uma vez que apontam para a potência da imagem em iluminar, mesmo que de modo fugaz, o vivido.

As fotografias nunca tiradas de Ana Marques estão investidas desse gesto e dessa exigência, uma vez que remetem ao desejo de recolher os vestígios, por menores que sejam, de uma existência, conferindo importância, dessa maneira, a esses pequenos e discretos eventos, que não devem, portanto, ser esquecidos. Assim, o trabalho da poeta diverge daquele movimento que se pode identificar na "história oficial dos livros", quer dizer, o registro de fatos passados e alheios à existência das pessoas comuns. Aqui, no poema "Museu", os fatos que "nunca aconteceram" são os que merecem ser transformados em monumentos, por contarem algo sobre nós mesmos, tudo aquilo que os grandes acontecimentos não incluem. Além disso, é importante notar que, nesse mundo em que a tecnologia digital impõe-se, com celulares capazes de capturar imagens, facilmente e com grande qualidade de definição, e redes sociais específicas para compartilhamento de fotos, as "fotografias não tiradas" constituem-se em uma impossibilidade, já que tudo parece ter sido fotografado à exaustão.

Se são as "fotografias nunca tiradas" que realmente importam, em contraste com a infinita quantidade de fotografias tiradas a cada instante, de todos os objetos e eventos possíveis, a poesia de Ana Marques parece dialogar com o seu tempo através de um deslocamento ou dissociação, nunca realmente indo ao encontro dele. Percebemos esse desencontro também no poema "[As casas pertencem aos vizinhos]", quando o eu lírico afirma que "[...] as fotografias por direito pertencem / aos que não saíram na fotografia" (2015, p. 60), remetendo a uma discussão muito frequente no campo da fotografia acerca de a quem pertence a foto tirada, conforme explica Roland Barthes:

O direito disse isso a seu modo: a quem pertence a foto? ao sujeito (fotografado)? ao fotógrafo? A própria paisagem não passa de uma espécie de empréstimo feito junto ao proprietário do terreno? Inúmeros processos, segundo parece, exprimiram essa incerteza de uma sociedade para a qual o ser baseava-se em ter. A fotografia transformava o sujeito em objeto, e até mesmo, se é possível falar assim, em objeto de museu (BARTHES, 1984, p. 26).

Talvez, ao realizar tais inversões - entregar as fotos às pessoas que não estão nelas, preencher um álbum com fotografias nunca tiradas -, a poeta espere evitar a museificação do 


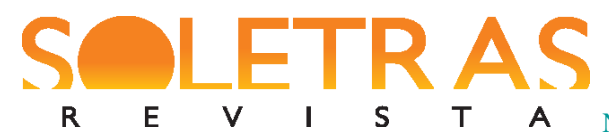

mundo, quer dizer, contrapondo-se, de um lado, à superexposição do sujeito que a prática da fotografia digital proporciona, e, de outro lado, à transformação de acontecimentos e pessoas em objeto de museu, daquele museu da ordem do sagrado, que separa os objetos e eventos do mundo cotidiano.

Evocando mais uma vez a posição de La Capra (2009), que afirma que "a história pode nunca capturar alguns elementos da memória: o sentimento de uma experiência, a intensidade da alegria ou do sofrimento, a qualidade daquilo que acontece" (p. 34), observamos que a poesia de Ana Marques parece voltar-se precisamente para esses aspectos fugidios da memória, de uma memória das subjetividades que os armazenadores da história (museus, monumentos, acervos, depósitos) não conseguem dar conta. Através de um convite ao cotidiano, ao detalhe, ao banal, a poeta busca ampliar uma visão de história (e de museu) para que nela possa caber também aquilo que normalmente não seria registrado, mas que contam muito sobre a nossa construção enquanto inseridos no mundo.

\title{
3. Os limites entre a permanência e a decadência
}

Outro tema bastante recorrente em $O$ livro das semelhanças é a passagem do tempo, seus efeitos sobre o corpo e a memória, e, ainda, uma reflexão sobre o que sobra depois da inevitável degradação de todas as coisas. É disso que trata o poema "[Podemos atear fogo]" onde o eu lírico, ao se expressar através da primeira pessoa do plural, enfatiza uma realidade que é vivida por todos nós, não somente pela poeta - ninguém está imune ao efeito que o decorrer dos anos tem sobre nossas vidas e corpos:

\author{
Podemos atear fogo \\ à memória da casa \\ desaprender um idioma \\ palavra por palavra \\ podemos esquecer uma cidade \\ suas ruas pontes armarinhos \\ armazéns guindastes teleféricos \\ e se ela tiver um rio \\ podemos esquecer o rio \\ mesmo contra a correnteza \\ mas não podemos proteger com o corpo \\ um outro corpo do envelhecimento \\ lançando-nos sobre a lembrança dele \\ (MARQUES, 2015, p. 59).
}




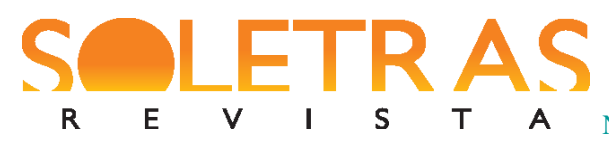

A poeta elenca uma série de situações improváveis, a partir das quais se estabelece uma metáfora para se refletir sobre a passagem do tempo e a perda da memória, como "desaprender um idioma" ou "atear fogo à memória da casa". Apesar de a "casa" ser algo físico, passível à destruição, a "memória da casa” está no plano das ideias — não seria suscetível ao fogo. No entanto, cabe lembrar que, frequentemente, a "memória" está associada a objetos físicos (fotos, roupas, móveis) e que estes, como afirma Jacques Derrida (2001), não têm uma durabilidade garantida e sedegradam com passar dos anos. Da mesma forma, é possível também esquecermos de cidades inteiras, não apenas em um nível individual, ao não lembrarmos mais de ruas e prédios de determinada cidade que visitamos, mas também em um nível coletivo, como no caso de Pripyat, na Ucrânia, criada para os trabalhadores da usina de Chernobyl e, após o acidente nuclear de 1986, abandonada, deixada em ruínas, esquecida.

Por melhor que consigamos realizar essas tarefas improváveis, "não podemos proteger com o corpo / um outro corpo do envelhecimento / lançando-nos sobre a lembrança dele". Se casas e cidades estão suscetíveis à destruição e esquecimento, o corpo, por definição frágil, não parece ter chance contra a ação do tempo. Embora a ciência avance e a indústria de cosmético invista em uma gama de produtos anti-envelhecimento, nada ainda foi feito para impedir o corpo de envelhecer.

Na memória, entretanto, a imagem de um corpo (a imagem de uma pessoa) muitas vezes se apresenta congelada, intacta. Uma das formas de proteção da memória contra a dispersão é justamente a fotografia, capaz de preservar a aparência de um corpo jovem para sempre - ou, pelo menos, enquanto o material do suporte fotográfico resistir. No poema "Aparador", Ana Marques discute esse uso cultural da fotografia, qual seja, o registro da memória, das vivências do sujeito:

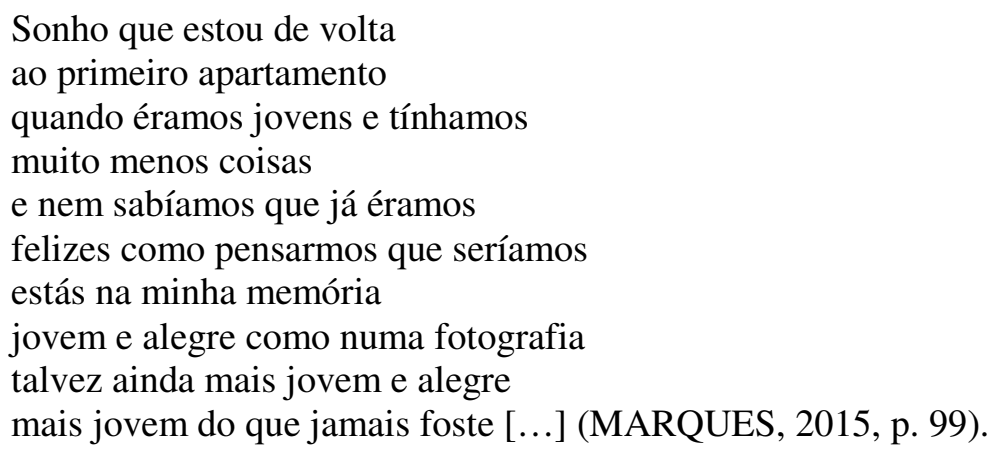


No excerto acima reproduzido, o eu lírico não se encontra propriamente diante de uma fotografia, no entanto, as imagens do passado, recuperadas em um sonho, possuem, por assim dizer, a nitidez de um registro fotográfico (“como numa fotografia"). Assim, a referência à fotografia parece conferir ao sonho uma materialidade que esse não possui, fixando e protegendo, desse modo, a rememoração da passagem do tempo - a imagem que se tem na memória, e que surge no sonho, não correria o risco de se perder nas lacunas das lembranças.

Mais adiante, no mesmo poema, a poeta reflete:

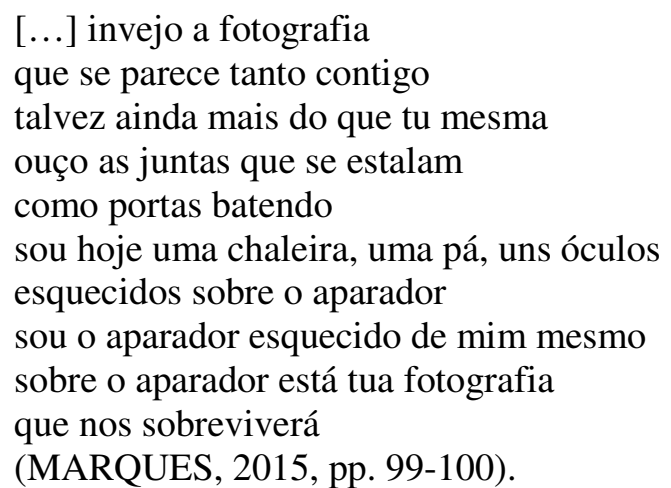

A inveja que se declara da fotografia pode ser lida como a percepção da passagem do tempo, sobretudo de suas marcas sobre o corpo e, provavelmente, o destino das pessoas retratadas, em contraste com o presente. Assim, a fotografia da mulher a quem o eu lírico se reporta, quando jovem, corresponde à imagem que dela se tem guardada na memória. Desse modo, a fotografia cumpre com seu papel cultural de arquivo do passado. Guardamos em nossos álbuns imagens que deixam de existir no mundo: pessoas que morreram, casas que ruíram, paisagens que foram alteradas. Entretanto, essa possibilidade de registro fidedignas do passado não se cumpre totalmente. Embora a fotografia auxilie o processo de preservação, ela não impede a ação do tempo, atuando, assim, como um simulacro, sempre anacrônica, sempre atrasada: um instante após ser fotografada, a pessoa retratada já não é a mesma do registro. Como afirma Barthes, "o que a fotografia reproduz ao infinito só ocorreu uma vez: ela repete mecanicamente o que nunca mais poderá repetir-se existencialmente" (1984, p. 13). Nos versos finais, a sobrevivência da fotografia sobre o aparador, dentre outros objetos, parece apontar para o problema de uma memória que persiste nos objetos, mesmo depois do desaparecimento ou dispersão dos eventos e pessoas a eles relacionados. 


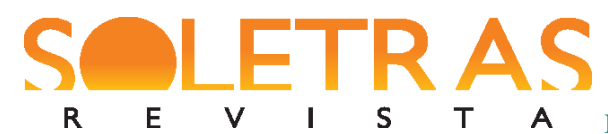

N.36 - 2018.2 - AULUS MANDAGARÁ MARTINS

MARIANE PEREIRA ROCHA

\section{Considerações finais}

Os poemas de $O$ livro das semelhanças nos levam a refletir sobre os mecanismos da memória, suas artes e armadilhas, para evocar o título de sua coletânea anterior (2014). O percurso construído por Ana Marques dá-se através de deslocamentos, daquilo que é inesperado: em relação à memória, o esquecimento; em relação à degradação, aquilo que resta; em relação às nossas decisões, aquilo que não fizemos; em relação à história, as subjetividades. Essas considerações acerca da memória e do esquecimento, aquilo que permanece e que se dispersa, são propostas por referências, diretas ou alusivas, à fotografia, cuja presença se manifesta em vários poemas do livro aqui em pauta. Como procuramos analisar, um dos usos culturais da fotografia é o registro de um evento passado. Desse modo, a imagem fotográfica constitui-se em um dispositivo da memória, auxiliando em sua preservação, permitindo a recuperação daquilo que a mente, por si só, já não é capaz de lembrar ou registrar. Nesse aspecto, vimos que a fotografia, nos poemas de Ana Marques, não apenas procura captar ou registrar os fatos significativos de uma existência, mas sobretudo aquilo que é banal e insignificante, e, até mesmo, aquilo que não foi fotografado. Esse paradoxo, as fotografias nunca tiradas, articula-se a uma reflexão sobre o que merece ser preservado e o que pode cair no esquecimento. Assim, a poeta propõe um museu de ninharias, de instantes banais, subvertendo o sentido comum atribuído à prática dos museus enquanto locais de armazenamento dos objetos e obras representativas da história e dos movimentos culturais ou artísticos.É, pois, a partir desses paradoxos que a poesia de Ana Marques questiona os limites da subjetividade envolvidos nos atos de memória e esquecimento, ao atribuir à fotografia a função de arquivo - um arquivo, no entanto, precário e frágil como o suporte que lhe confere materialidade, e que, como tal, não será imune à passagem do tempo e de seus efeitos sobre o sujeito.

\section{Referências}

AGAMBEN, G. O Dia do Juízo; Um elogio às profanações. Profanações. Trad. Selvino J. Assmann. São Paulo: Boitempo, 2007, p. 27-30; 65-79.

AGAMBEN, G. $O$ que é o contemporâneo? E outros ensaios. Trad. Vinícius Nicastro Honesko. Chapecó, SC: Argos, 2009.

BARTHES, R. A câmara clara: nota sobre a fotografia. Trad. Júlio Castañon Guimarães. Rio de janeiro: Nova fronteira, 1984. 
BAUDELAIRE, C. As flores do mal. Trad. Ivan Junqueira. Rio de Janeiro: Nova Fronteira, 1985.

BENJAMIN, W. Charles Baudelaire: um poeta na época do capitalismo avançado. Baudelaire e a modernidade. Trad. João Barrento. Belo Horizonte: Autêntica, 2015.

Pequena história da fotografia. In: - Magia e técnica, arte e política: ensaios sobre literatura e história da cultura. Trad. Sergio Paulo Rouanet. São Paulo: Brasiliense, 1985, p. 91-108.

DERRIDA, J. Mal de arquivo: uma impressão freudiana. Trad. Claudia de Moraes Rego. Rio de Janeiro: Relume Dumará, 2001.

LACAPRA, D. Historia y memora después de Auschiwitz. Trad. Alejandro Sepúlveda. Buenos Aires: Prometo Libros, 2009.

MACHADO, A. A ilusão especular. São Paulo: Gustavo Gili, 2015.

MARQUES, A. O livro das semelhanças. São Paulo: Companhia das Letras, 2015.

RESENDE, B. Questões da ficção brasileira do século XXI. Revista Grumo, v. 6, n. 2, dez. 2007. Disponível em: http://www.beatrizresende.com.br/questoes-da-ficcao-brasileira-noseculo-xxi/. Acesso em $10 \mathrm{dez} .2017$.

\title{
Museum of moments: poetry, memory and photography in Ana Martins Marques
}

\begin{abstract}
This essay aims to analyze the relation between poetry, memory and photography in Ana Martins Marques' poetry, particularly in the poems "Museu" and "Aparador", from $O$ livro das semelhanças (2015). It is our interest to investigate how the memory's thematic presents itself in Marques' poetry, especially about the photograph while a device that stores the past. Therefore, Agamben's reflections $(2007 ; 2009)$ about the museification of the world and the photographic picture provide important theoretical perspectives to the proposed work. We verified, through this study, that the photography in Ana Marques' poems, captures or registers not only the meaningful facts of the existence, but, especially, the things that are banal and insignificant, even the things that weren't photographed. Therefore, the poet comes up with a museum of trifles, of banal instants, subverting the common meaning assigned to the museum practice while a place that storages objects and works representatives of history and cultural and artistic movements.
\end{abstract}

Keywords: Contemporary Brazilian poetry. Photography. Memory. Ana Martins Marques.

Recebido em: 06 de junho de 2018.

Aceito em: 09 de agosto de 2018. 